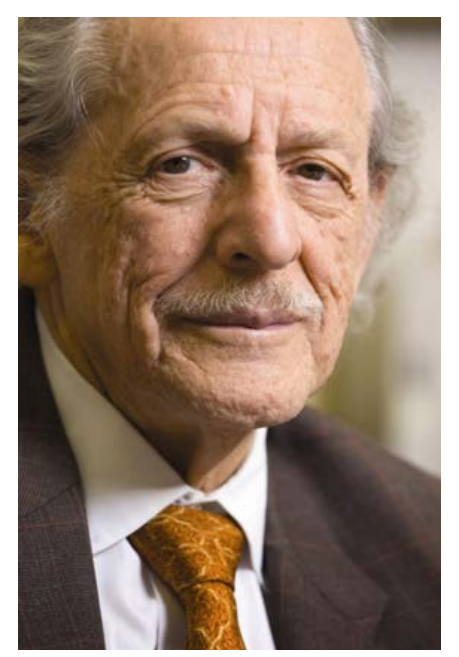

Eugene Garfield

\title{
Measuring \\ Academic Impact
}

Svetla Baykoucheva

White Memorial Chemistry Library

sbaykouc@umd.edu

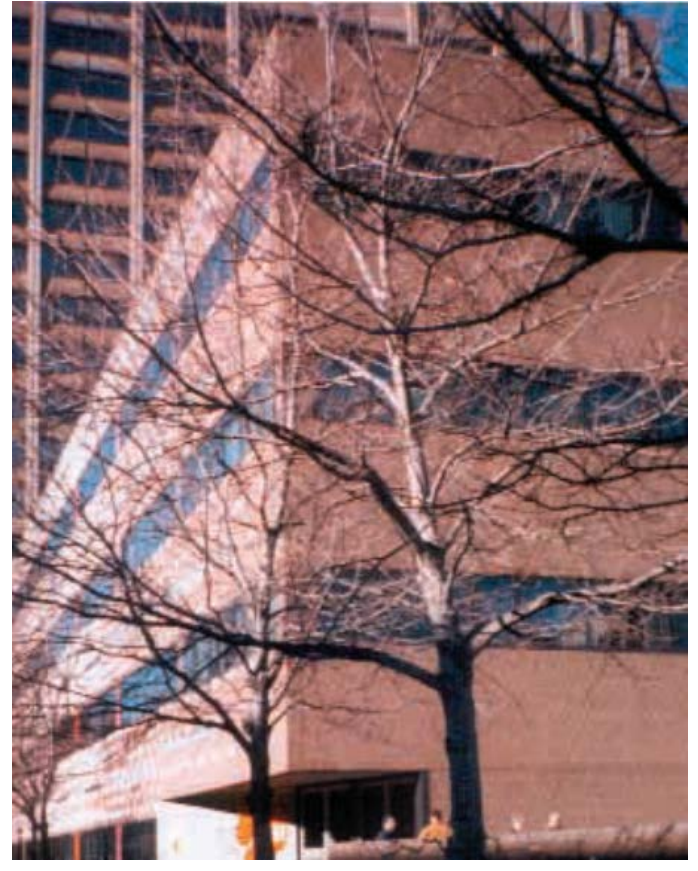

The Institute for Scientific Information (ISI) at 3501 Market Street, Philadelphia 


\section{The Science Citation Index (SCI)}

- The $\mathrm{SCl}$ was created by Eugene Garfield in the early 60s.

- He founded the Institute for Scientific Information (ISI), which was later acquired by ThomsonReuters

- Web of Science is based on the $\mathrm{SCl}$

- Journal Impact Factors (IFs) are published in Journal Citation Reports

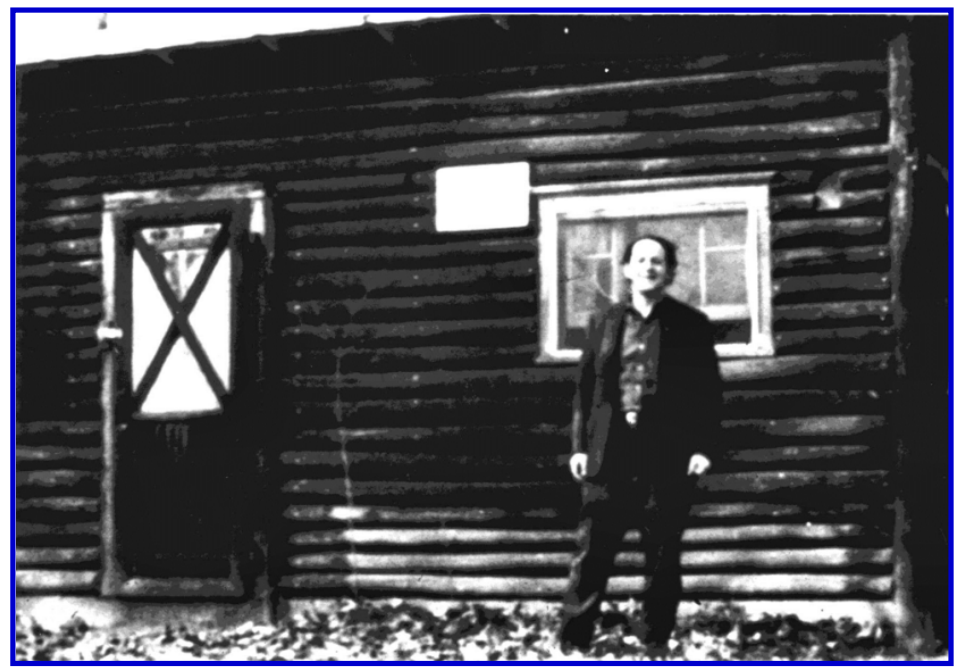

The converted chicken coop in Thorofare, NJ, where $\mid \mathrm{SI}{ }^{\circledR}$ began 


\section{Journal Impact Factor ${ }^{\mathrm{TM}}$ (IF)}

- The IF of a particular journal is the ratio between the number of times articles published in the journal were cited, divided by the number of citable articles published in this journal during the same period of time.

- The IF of a journal for the year 2010 is calculated as follows: the number of citations made in 2010 to papers published in a journal during the previous two years (2008 and 2009) is divided by the number of citable articles published in the same two-year period. 


\section{Drawbacks of IFs}

- Concealed and flawed calculation

- Does not take into account self-citations or negative citations

- Includes limited number of journals

- English-language biased

- Can be misused by editors by publishing reviews as editorials

- Authors may avoid citing their competitors 


\section{Journal Citation Reports (JCR) (Chemistry)}

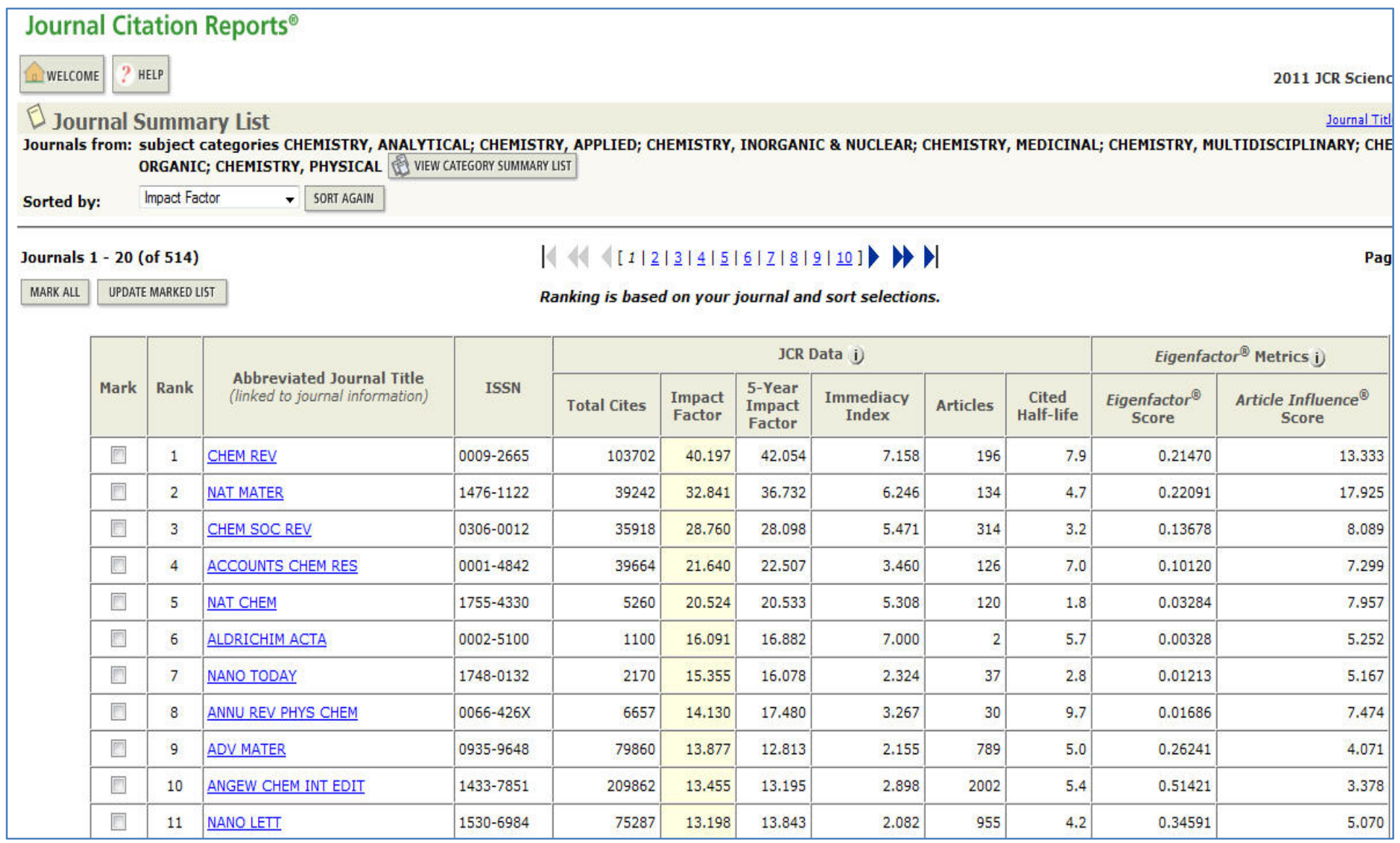




\section{Web of Science: Cited Reference Search}

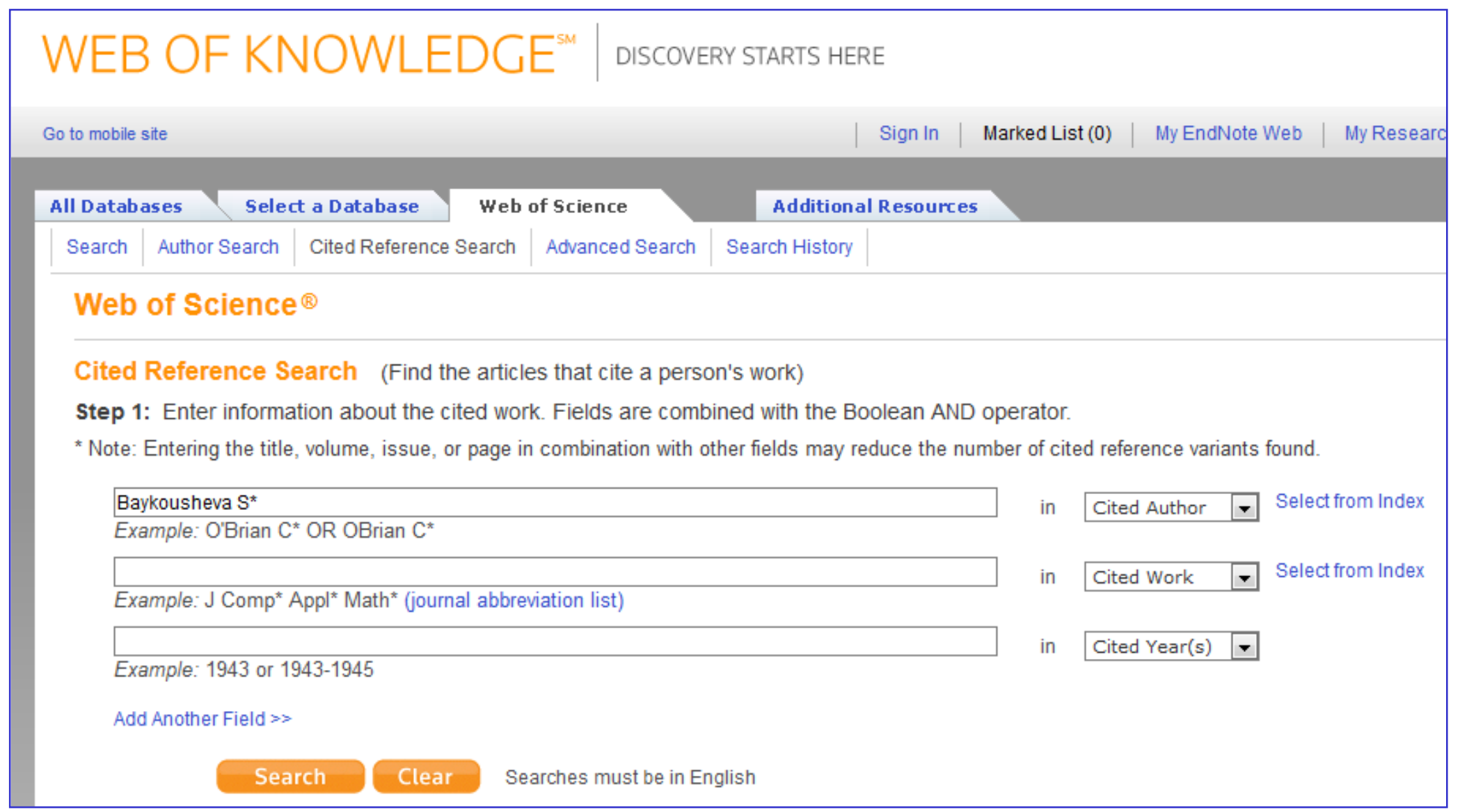




\section{Web of Science Citations}

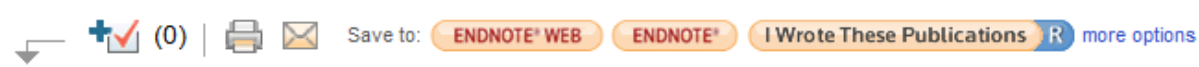

E Analyze Results

$\square$ 1. Title: Regulation of the biosynthesis of 4,7,10,13,16-docosapentaenoic acid

Author(s): Mohammed, BS; Luthria, DL; Baykousheva, SP; et al.

Source: BIOCHEMICAL JOURNAL Volume: 326 Pages: 425-430 Part: Part 2 Published: SEP 11997

Times Cited: 16 (from Web of Science)

Sfind it [ $\boxplus$ View abstract ]

2. Title: Reevaluation of the pathways for the biosynthesis of polyunsaturated fatty acids Author(s): Sprecher, H; Luthria, DL; Mohammed, BS; et al.

Source: JOURNAL OF LIPID RESEARCH Volume: 36 Issue: 12 Pages: 2471-2477 Published: DEC 1995 Times Cited: 239 (from Web of Science)

Sfind it [ $⿴ 囗$ View abstract ]

3. Title: PEROXISOMAL-MICROSOMAL COMMUNICATION IN UNSATURATED FATTY-ACID METABOLISM

Author(s): BAYKOUSHEVA, SP; LUTHRIA, DL; SPRECHER, H 20 DOI: 10.1016/0014-5793(95)00565-Q Published: JUN 261995

Times Cited: 18 (from Web of Science)

Gfind it [ $⿴ 囗$ View abstract ]

4. Title: DOUBLE-BOND REMOVAL FROM ODD-NUMBERED CARBONS DURING PEROXISOMAL BETA-OXIDATION OF ARACHIDONIC-ACID REQUIRES BOTH 2,4-DIENOYL-COA REDUCTASE AND DELTA(3,5),DELTA(2,4)-DIENOYL-COA ISOMERASE

Author(s): LUTHRIA, DL; BAYKOUSHEVA, SP; SPRECHER, H

Source: JOURNAL OF BIOLOGICAL CHEMISTRY Volume: 270 Issue: 23 Pages: 13771-13776 Published: JUN 91995

Times Cited: 34 (from Web of Science)

Sfind it [ $₫$ View abstract ]

5. Title: DIFFERENCES IN THE REGULATION OF BIOSYNTHESIS OF 20-CARBON VERSUS 22-CARBON POLYUNSATURATED FATTY-ACIDS Author(s): SPRECHER, HW; BAYKOUSHEVA, SP; LUTHRIA, DL; et al.

Source: PROSTAGLANDINS LEUKOTRIENES AND ESSENTIAL FATTY ACIDS Volume: 52 Issue: $2-3$ Pages: 99-101 DOI: 10.1016/0952-3278(95)90005-5 Published: FEB-MAR 1995

Times Cited: 5 (from Web of Science)

Sfind it 


\section{Web of Science Citations/h-index}

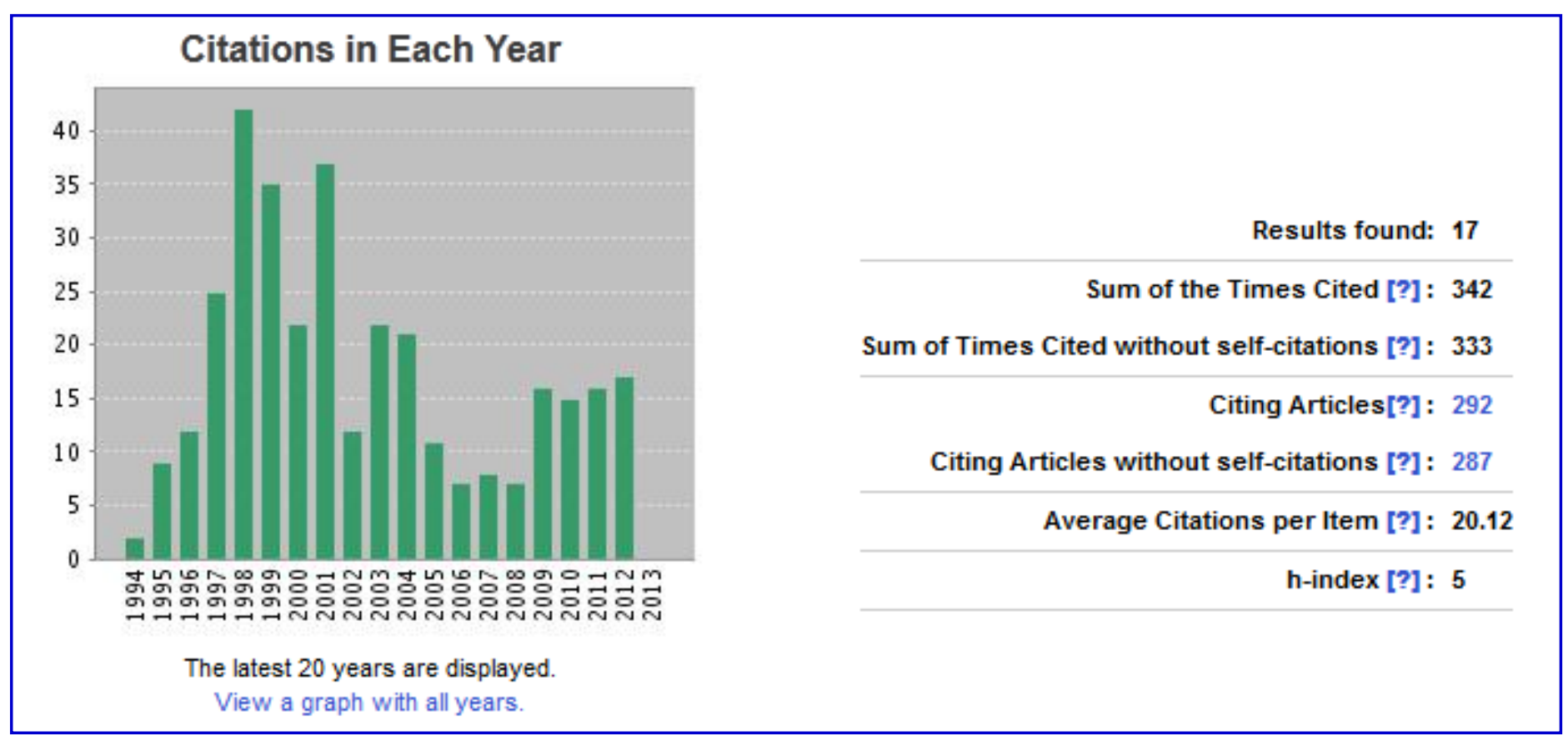




\section{The h-index}

- The value of $\mathrm{h}$ is equal to the number of papers $(\mathrm{N})$ in the list that have $\mathrm{N}$ or more citations.

- An h-index of 20 means there are 20 items that have 20 citations or more.

- This metric is useful because it discounts the disproportionate weight of highly cited papers or papers that have not yet been cited.

- Favors academics that publish a continuous stream of papers with lasting and above-average impact

- Developed by J.E. Hirsch in 2005 


\section{Google Scholar Citations}

- Sign to your Google account

- The Citations sign up form will ask you to confirm the spelling of your name, and to enter your affiliation, interests, etc.

- On the next page, you'll see groups of articles written by people with names similar to yours. Click "Add all articles" next to each article group that is yours, or "See all articles" to add specific articles from that group.

- If you don't see your articles in these groups, click "Search articles" to do a regular Google Scholar search, and then add your articles one at a time. Feel free to do as many searches as you like. 


\section{Example of Google Scholar Citations}

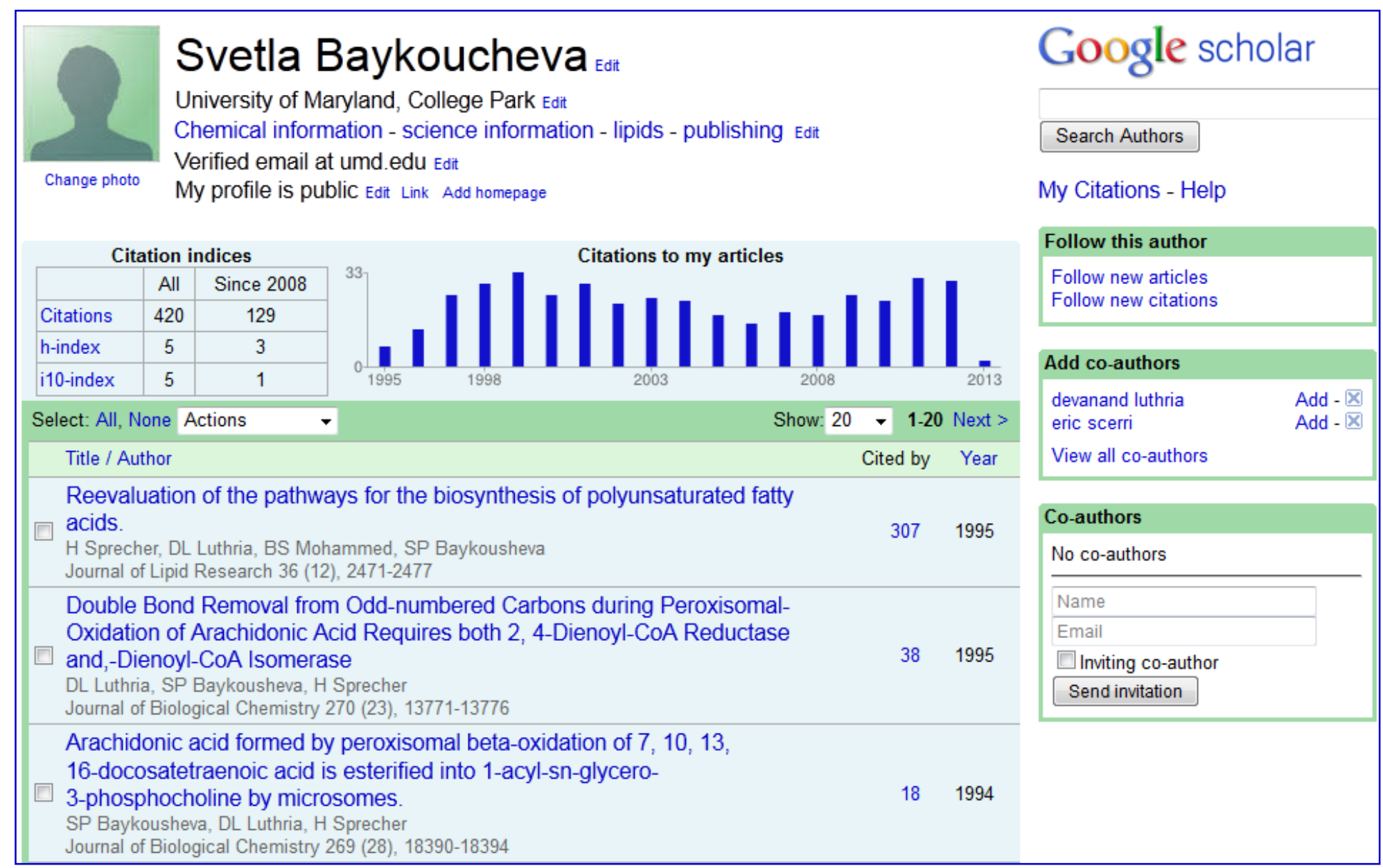




\section{Scopus Journal Analyzer}

\section{Multiple Metrics. One Place.}

Using the metrics in the Journal Analyzer, Librarians and Researchers can objectively assess all of the journals which are indexed in Scopus to make informed decisions on collection development and article submissions.

- SJR

- SNIP

- Documents

- Percent Review

- Percent not cited

- Number of citations

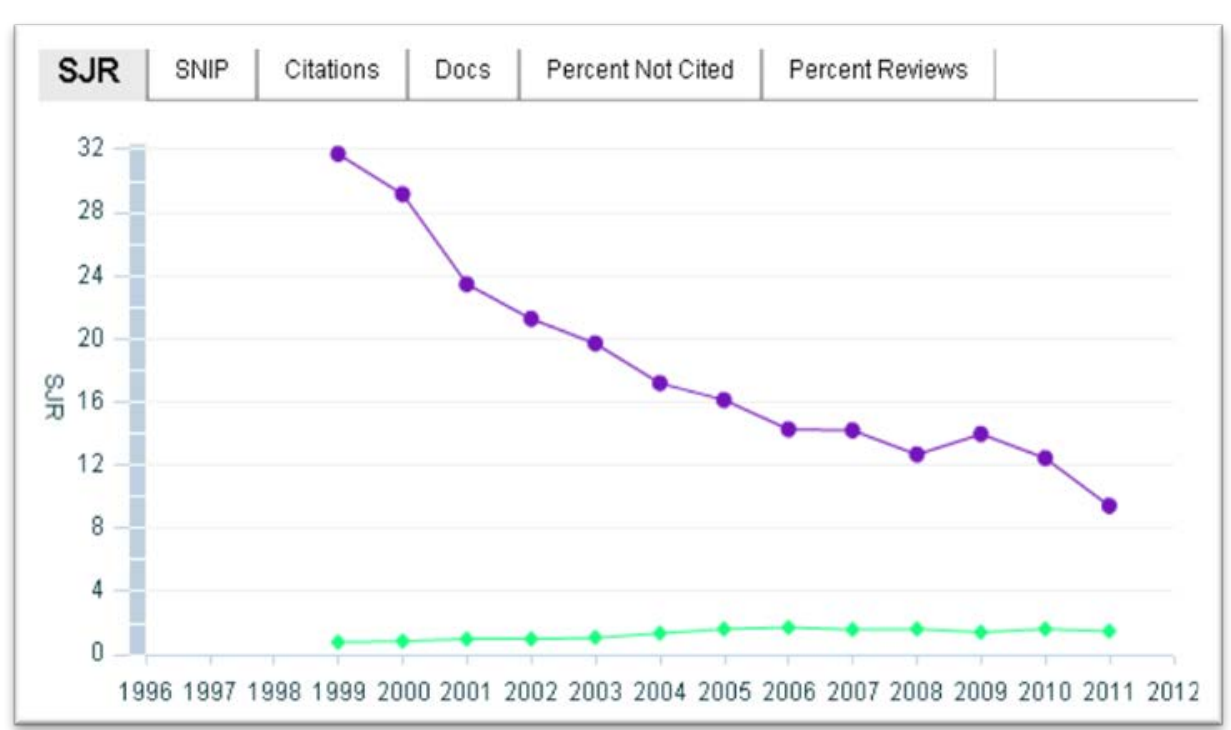




\section{Impact Factor ${ }^{\mathrm{TM}}$}

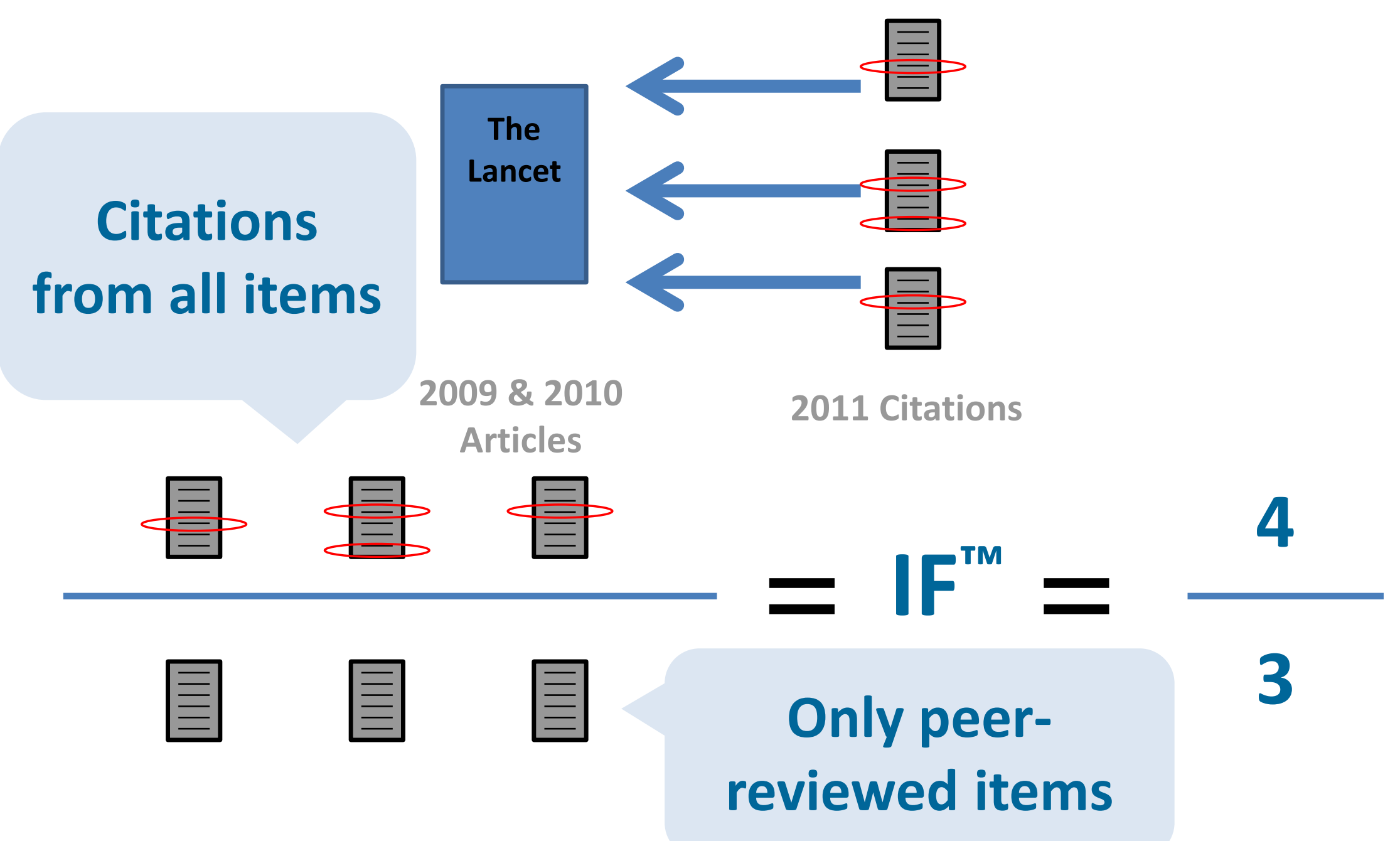




\section{www.journalmetrics.com}

\section{SNIP: Balancing the scales}

Created by Professor Henk Moed at CTWS, University of Leiden, Source-Normalized Impact per Paper (SNIP) measures contextual citation impact by weighting citations based on the total number of citations in given subject field. The impact of a single citation is given a higher value in subject areas where citations are less likely, and vice versa.

\section{About SNIP}

- Measures contextual citation impact by 'normalizing' citation values

- Takes a research field's citation frequency into account

- Considers immediacy - how quickly a paper is likely to have an impact in a given field

- Accounts for how well the field is covered by the underlying database

- Calculates without use of a journal's subject classification to avoid delimitation

\section{SJR: The power of prestige}

Developed by Professor Félix de Moya, SCImago Journal Rank (SJR) is a prestige metric based on the idea that 'all ciltations are not created equal'. With SJR, the subject field, quality and reputation of the journal has a direct impact on the value of a citation. This means that a citation from a source with a relatively high SJR is worth more than a citation from a source with a lower SJR.

\section{About SJR}

- Is weighted by the prestige of the journal, thereby 'leveling the playing field' among journals.

- Eliminates manipulation: the only way to raise the SJR ranking is to be published in more reputable journals.

- 'Shares' a journal's prestige equally over the total number of citations in that journal. 


\section{Bibliometrics}

Impact Factor $^{\mathrm{TM}} \quad$ SNIP \& SJR

Metric

$1^{\text {st }}$ Generation

$2^{\text {nd }} \& 3^{\text {rd }}$ Generation

Equation

Concealed

Transparent

Coverage

10,000

19,500

Citation Window

$2 \& 5$ years

3 years 


\section{SNIP - "Balancing the Scales"}

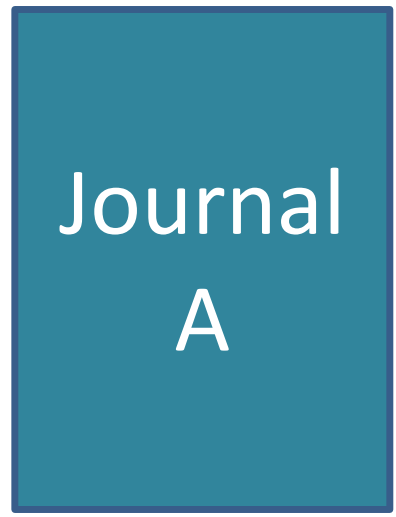

100 Citations

Biomedical Engineering

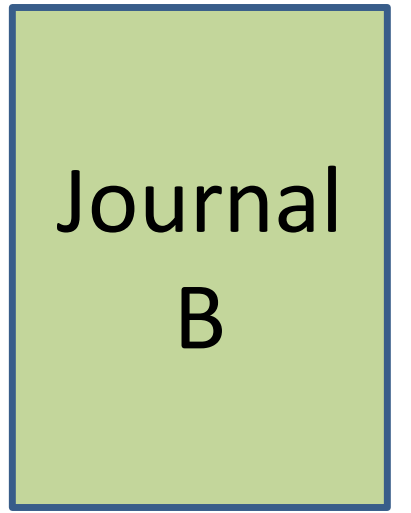

50 Citations

\section{SNIP Normalization: \\ Life Sciences - high impact and high citation potential Social Science - low impact and low citation potential}

- SNIP normalizes for different citation patterns within subject areas, allowing for comparison between Journal A and Journal B

- When using SNIP you can be sure that differences are due to journal quality and not subject area citation behaviour 


\section{SNIP Key takeaways}

- Ability to compare titles from different subject fields

- Only uses peer-reviewed items when calculating impact 


\section{SJR - "The power of prestige"}

Journal A will have a higher SJR than Journal B

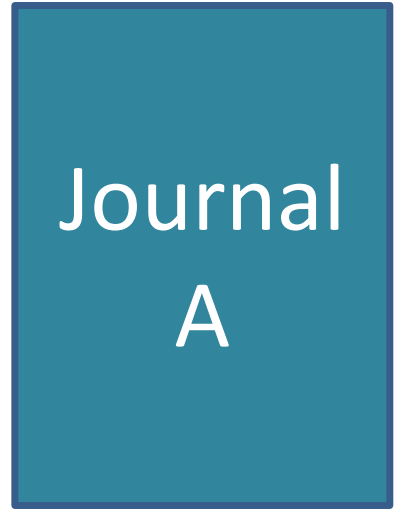

100 Citations

High Prestige Titles

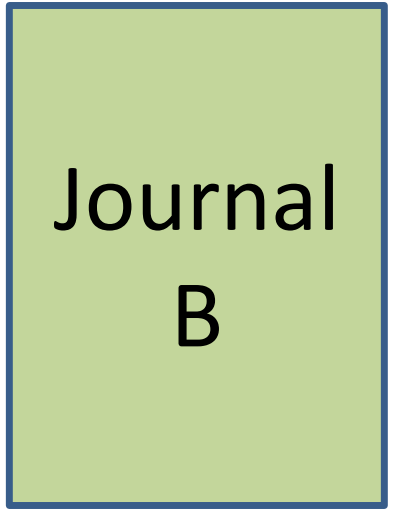

100 Citations

Low Prestige Titles

- Impact Factor is a metric measuring popularity summing up all citations a journal receives regardless of the status of the citing journal

-When calculating the SJR quality and reputation of a citing journal has a direct effect on the value of citations 


\section{SJR Key takeaways}

- Identifies a Journal's intricate citation networks

- Aims to limit excessive benefits derived from self citation by discounting journal self-citations once they exceed $1 / 3$ of the total citations received by a journal 


\section{SJR Journal Ranking (Chemistry)}

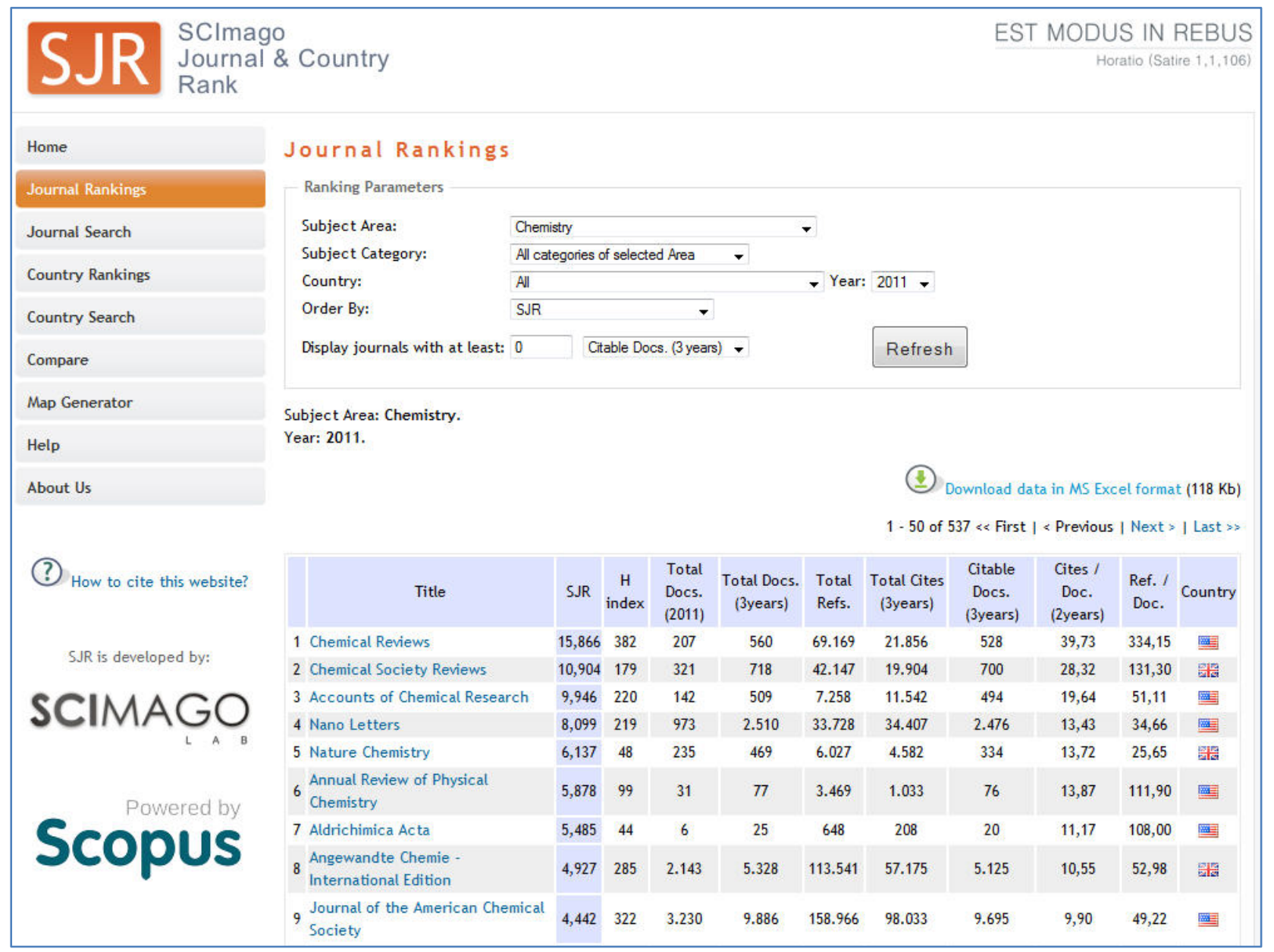




\section{SJR (Chemistry)}

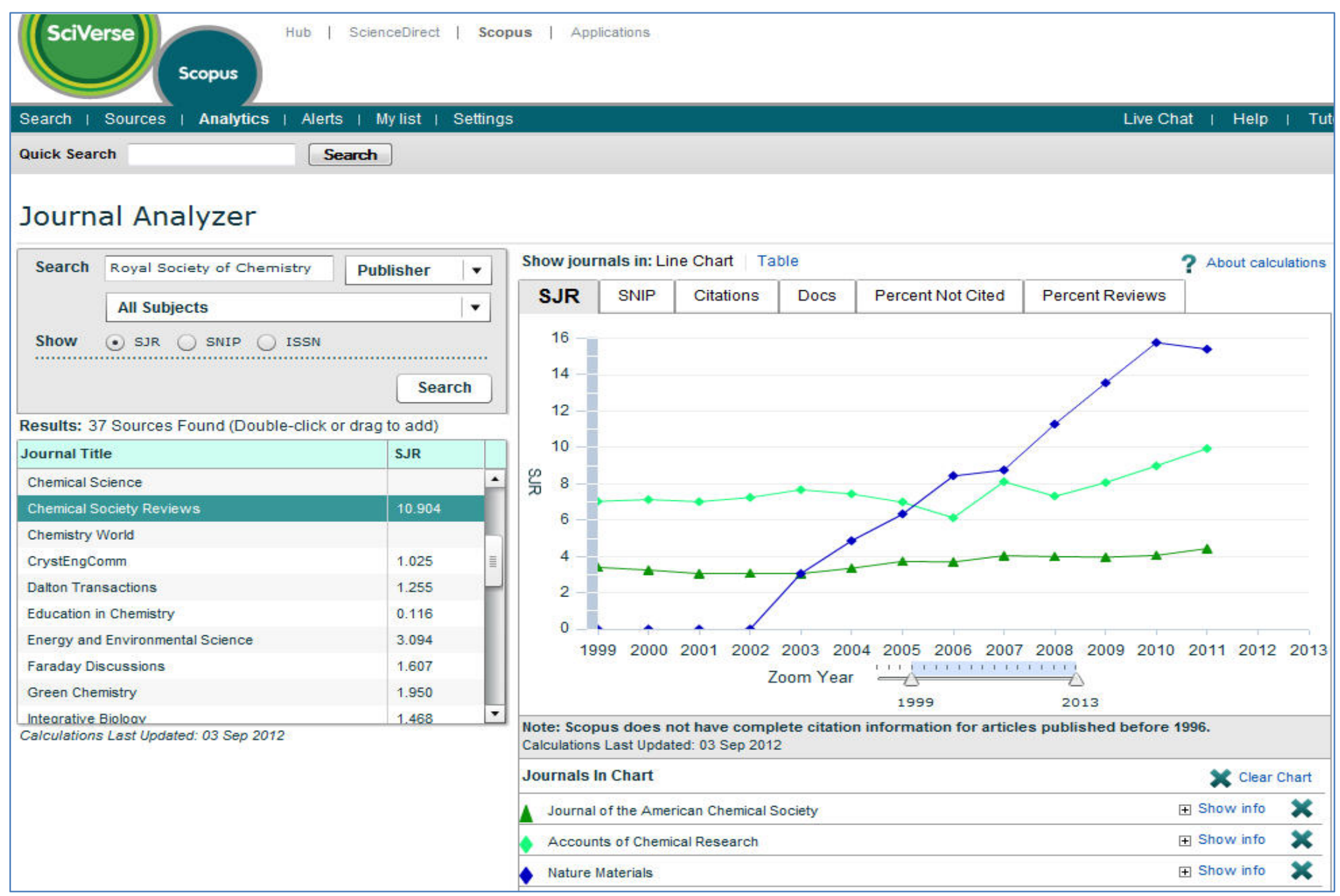




\section{The Challenge: Scholarly Name Ambiguity}

Many researchers that too closely resemble one another.
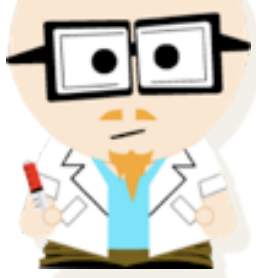

Dr. Smith Dr. Smith Dr. Smith
Researchers publish under name variations.

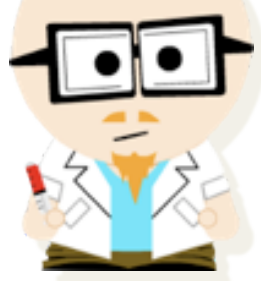

Dr. Smith

Dr. J. Smith Dr. James Smith 


\section{Scopus Profile Organization}

\section{The Vast Universe of Research}

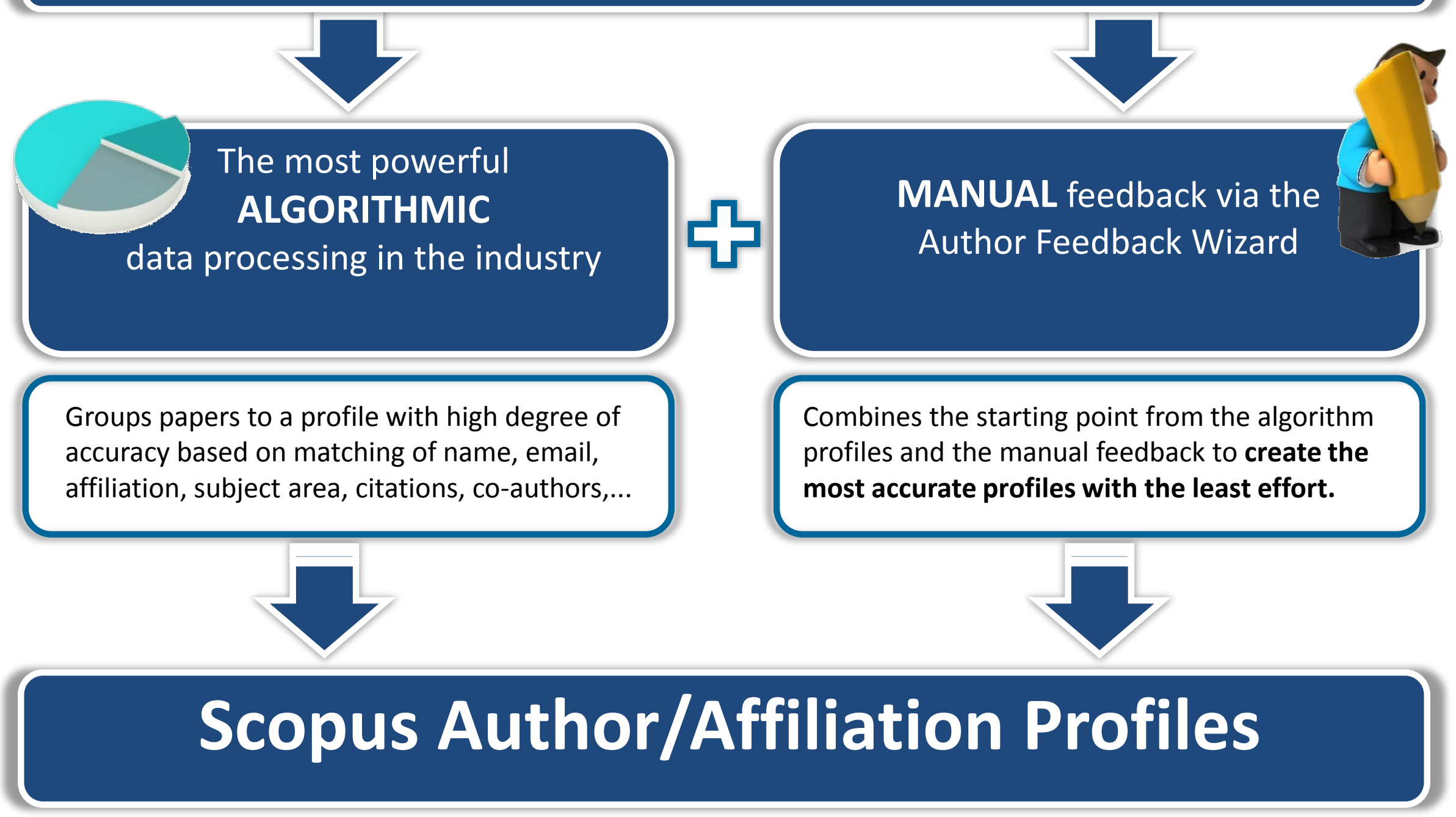




\section{Scopus Author Searching}

\section{Make Author Selection}

Author Last Name

Baykoucheva

E.g., smith

Affiliation

E.g., university of toronto
Initials or First Name

E.g., j.l.
Show exact matches only

To determine which author names should be grouped together under a single identifier number, the Scopus Author Identifier uses an algorithm that matches author names based on their affiliation, address, subject area, source title, dates of publication, citations, and co-authors. Documents with

insufficient data may not be matched, this can lead to more than one entry in the results list for the same author. By default, only details pages matched to more than one document in Scopus are shown in search results. About Scopus Author Identifier

\begin{tabular}{|c|c|c|c|c|c|c|c|c|c|c|}
\hline & « & \multicolumn{5}{|c|}{ Author results: 2} & \multicolumn{4}{|r|}{1 of 1} \\
\hline $\begin{array}{l}\text { Refine results } \\
\qquad \text { Limit to }\end{array}$ & & \multicolumn{2}{|c|}{$\begin{array}{l}\square \text { All } \\
\square \text { Page }\end{array}$} & \multicolumn{2}{|c|}{ 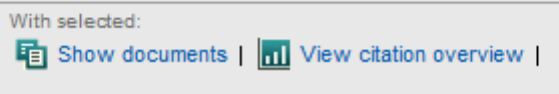 } & quest to merge aut & & \multirow[t]{2}{*}{ Sort by } & \multicolumn{2}{|c|}{ Document Count (Descending) $\overrightarrow{ }$} \\
\hline Source Title & $\hat{\hat{\lambda}}$ & & Auth & & Documents & Subject Area & Affiliation & & City & Country \\
\hline $\begin{array}{l}\square \text { Acta Microbiologica } \\
\text { Bulgarica } \\
\square \text { Acta Microbiologica } \\
\text { Virulogica Et } \\
\text { Immunologica } \\
\square \text { Cancer Letters }\end{array}$ & $\begin{array}{l}\text { (1) }> \\
\text { (1) }>\end{array}$ & $\square_{1}^{\square}$ & $\begin{array}{l}\text { Bay } \\
\text { Bayk } \\
\text { Bayk } \\
\text { Bayk }\end{array}$ & $\begin{array}{l}\text { kousheva, Svetla P. } \\
\text { :ousheva, Svetla } \\
\text { :ousheva, S. P. } \\
\text { :ousheva Sv., Svetla }\end{array}$ & $\begin{array}{l}\text { 自 } 16 \\
\text { 坾 Show Last Title }\end{array}$ & $\begin{array}{l}\text { Biochemistry, } \\
\text { Genetics and } \\
\text { Molecular Biology; } \\
\text { Medicine; } \\
\text { Immunology and } \\
\text { Microbiology; ... }\end{array}$ & University of Maryland & & College Park & United States \\
\hline $\begin{array}{l}\square \text { Chemical Innovation } \\
\text { FEBS Letters } \\
\text { View more }\end{array}$ & $\begin{array}{l}\text { (1) }> \\
\text { (1) }>\end{array}$ & 2 & $\begin{array}{l}\text { Bay } \\
\text { Bayk }\end{array}$ & $\begin{array}{l}\text { koucheva, Svetla } \\
\text { oucheva, S. }\end{array}$ & $\begin{array}{l}\text { 兒 } 4 \\
\text { 桪 Show Last Title }\end{array}$ & $\begin{array}{l}\text { Social Sciences ; } \\
\text { Chemical } \\
\text { Engineering ; } \\
\text { Engineering; ... }\end{array}$ & University of Maryland & & College Park & United States \\
\hline
\end{tabular}




\section{Select the author profiles you'd like to merge and launch the Feedback Wizard}

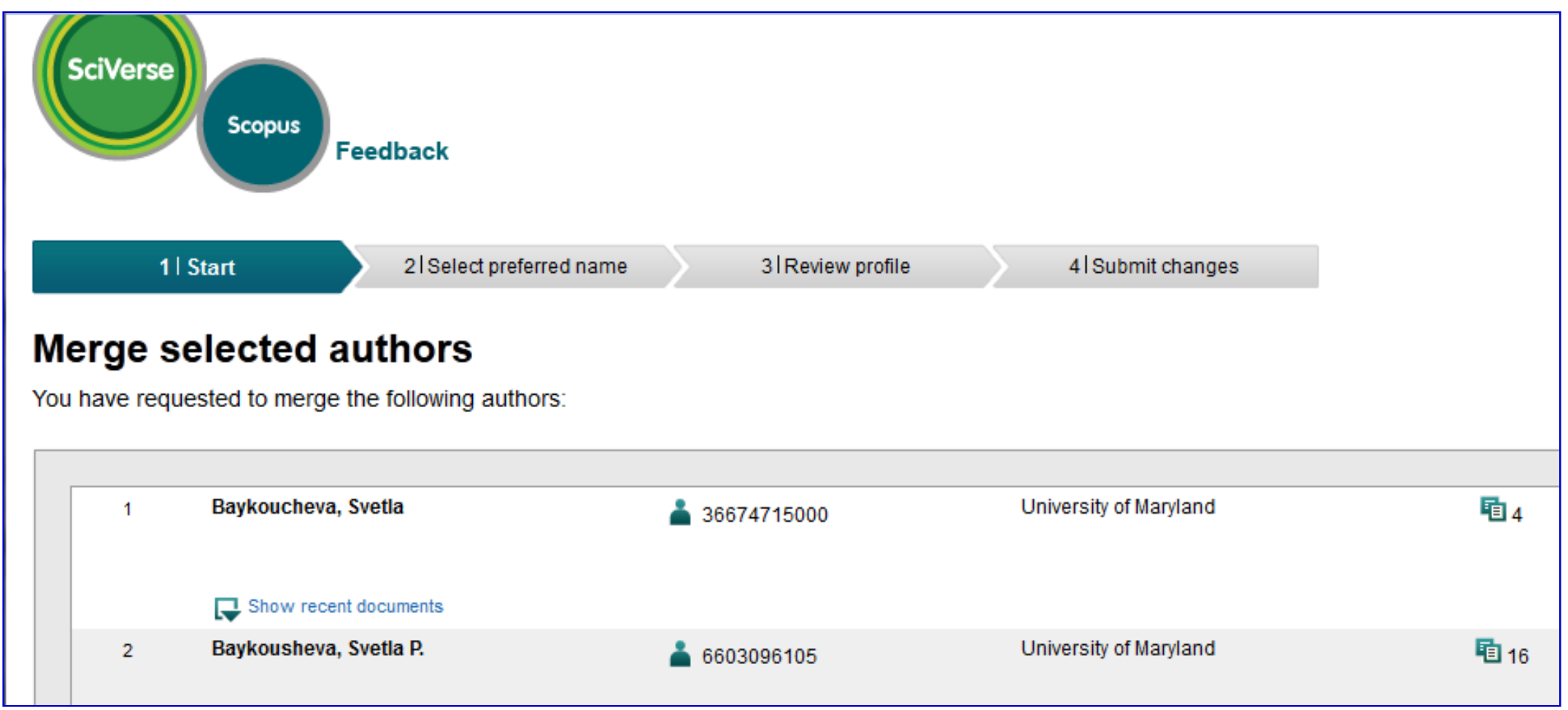




\section{ORCID: Connecting Research \& Researchers}

\section{ORCID Mission:}

ORCID aims to solve the name ambiguity problem in research and scholarly communications by creating a central registry of unique identifiers for individual researchers

Open

Researcher \&

Contributor

ID

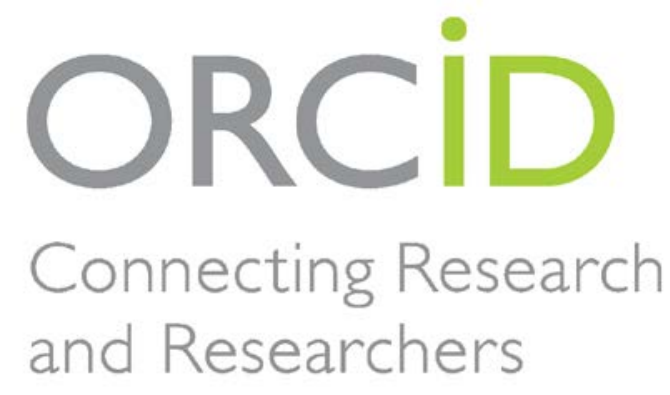




\section{Scopus2ORCID: Easy ORCID Set Up orcid.scopusfeedback.com}

\begin{tabular}{|c|c|}
\hline \multirow{2}{*}{\multicolumn{2}{|c|}{$\begin{array}{l}\text { Search | Souroes | Analytics | Alerts | My list | Settings } \\
\text { Quick Search }\end{array}$}} \\
\hline & \\
\hline \multicolumn{2}{|c|}{ Back to results 1 of 23 Next $>$} \\
\hline \multicolumn{2}{|c|}{ 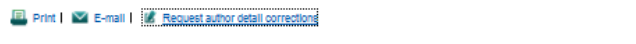 } \\
\hline \multicolumn{2}{|c|}{ Smith, Jacob A D } \\
\hline Personal & Fins postertal a anor mascones \\
\hline Name & Smith, Jacob A D \\
\hline Other formats & 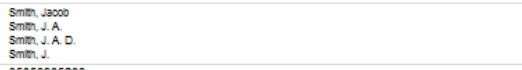 \\
\hline $\begin{array}{l}\text { Author ID } \\
\text { Affililation }\end{array}$ & $\begin{array}{l}35353935200 \\
\text { Aniversity of Texas at Arington, Department of Physics. } \\
\text { Arlington } \\
\text { United States }\end{array}$ \\
\hline \multicolumn{2}{|r|}{ ( } \\
\hline Doouments & 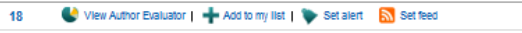 \\
\hline $\begin{array}{l}\text { Referenoes } \\
\text { Citations }\end{array}$ & 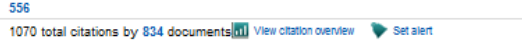 \\
\hline hindex & 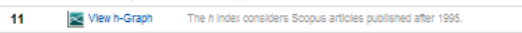 \\
\hline $\begin{array}{l}\text { Co-3uthors } \\
\text { Web search }\end{array}$ & 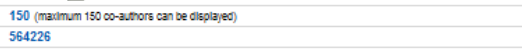 \\
\hline Subject area & $\begin{array}{l}\text { Physics and Astronomy } \\
\text { Mathematios } \\
\text { Medicine } \\
\text { Morie... }\end{array}$ \\
\hline I Find potentia & author matches \\
\hline
\end{tabular}

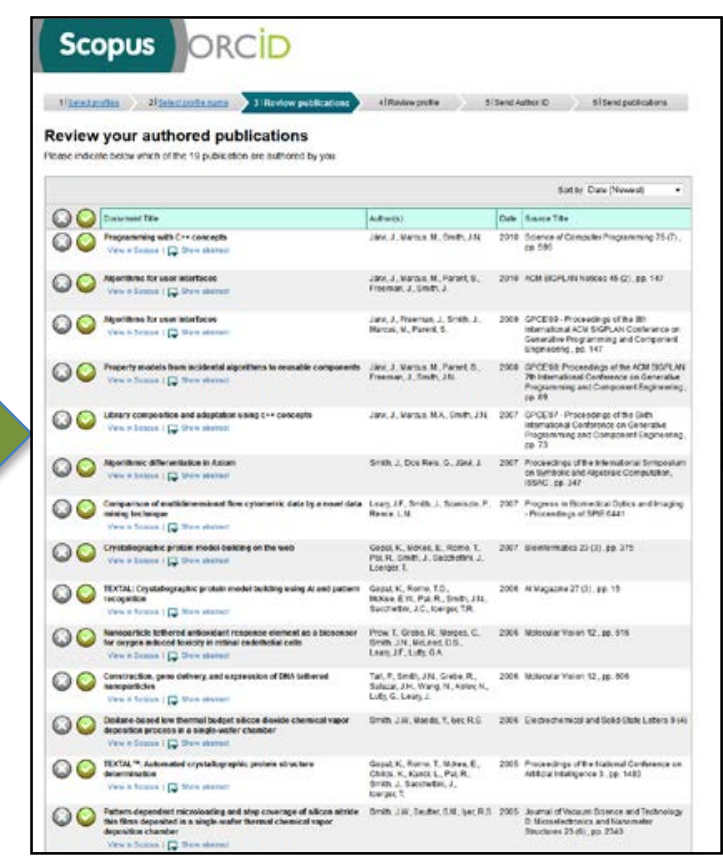

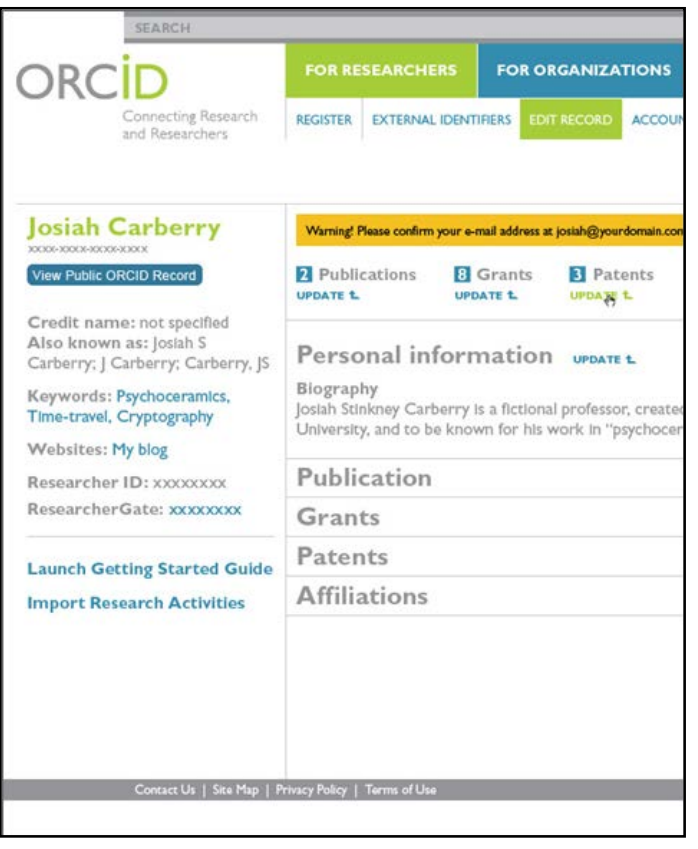

Enter via Scopus2ORCID Wizard or from ORCID! 


\section{Scpous2ORCID: Benefits}

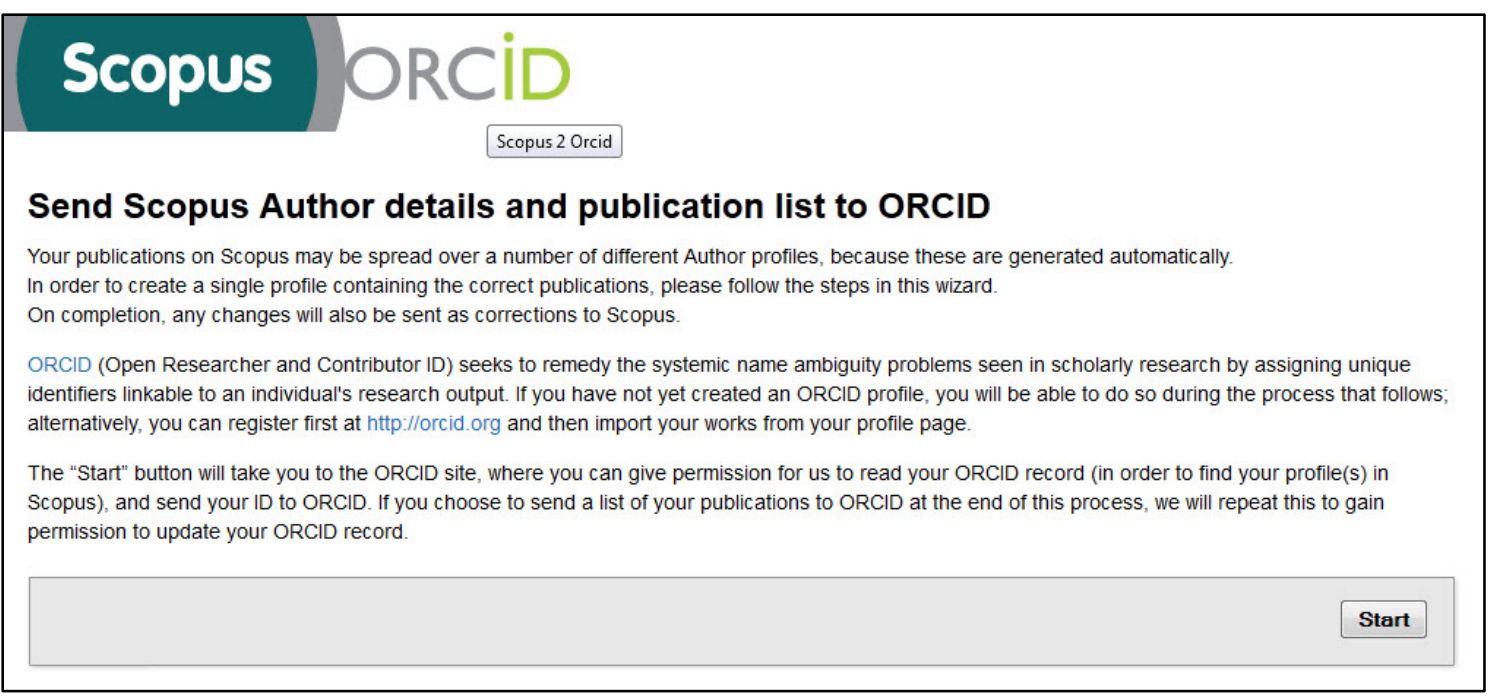

Save Time

Importing your authors' information from Scopus is faster and more accurate than manually entering information in ORCID.

\section{Improve Your Researchers' Scopus Author Profiles}

Changes made while using the wizard will be processed in Scopus Author Profiles (approximate time: 8 weeks) 


\section{Scopus Tools \& Features}

- Scopus Profiles Feedback Wizard \& ORCID

- Citation Tracker in Scopus

- Author Evaluator Tool 


\section{Select Show Documents}

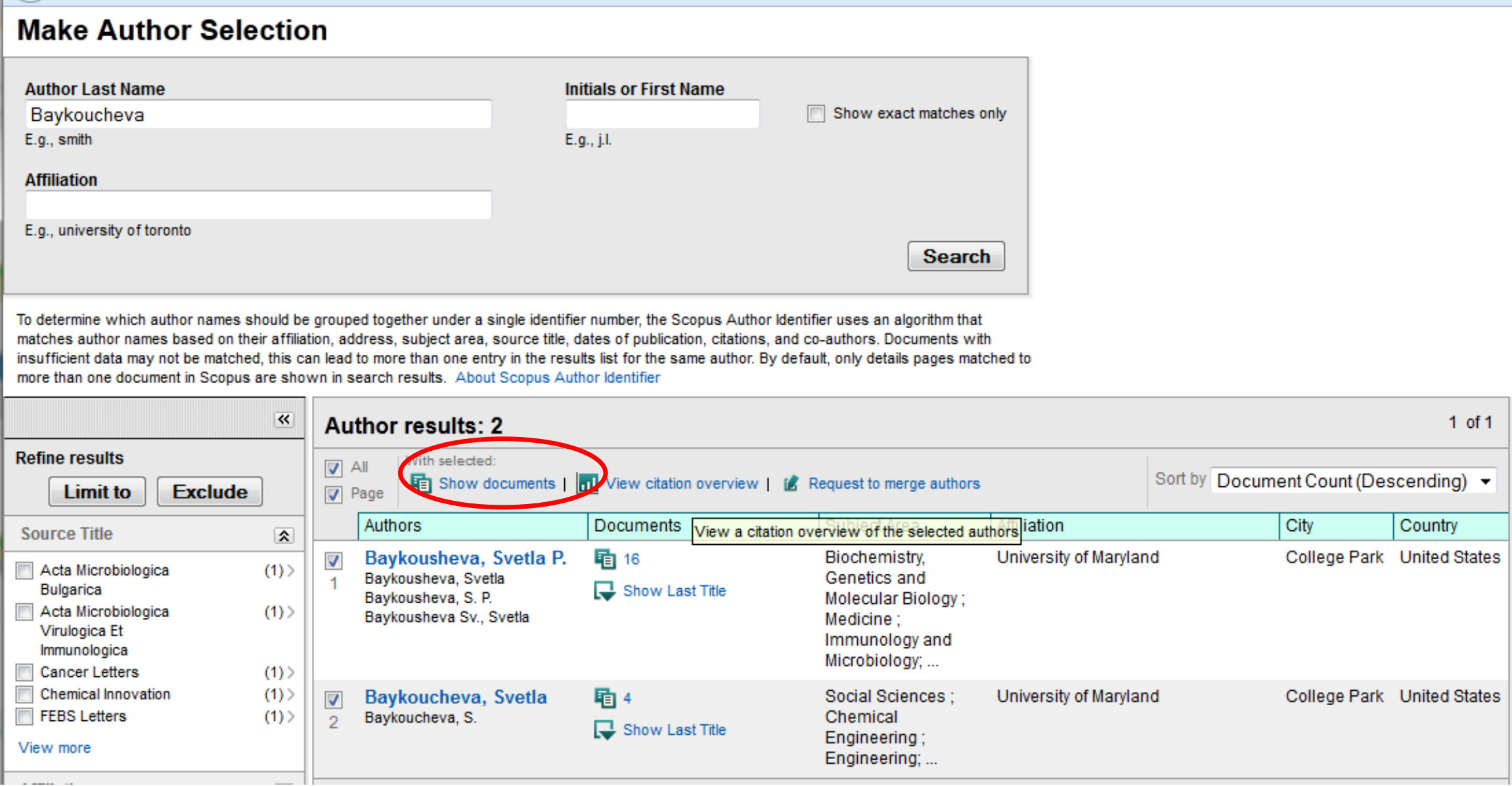




\section{Analyze Citations Received for the Selected Group of Documents}

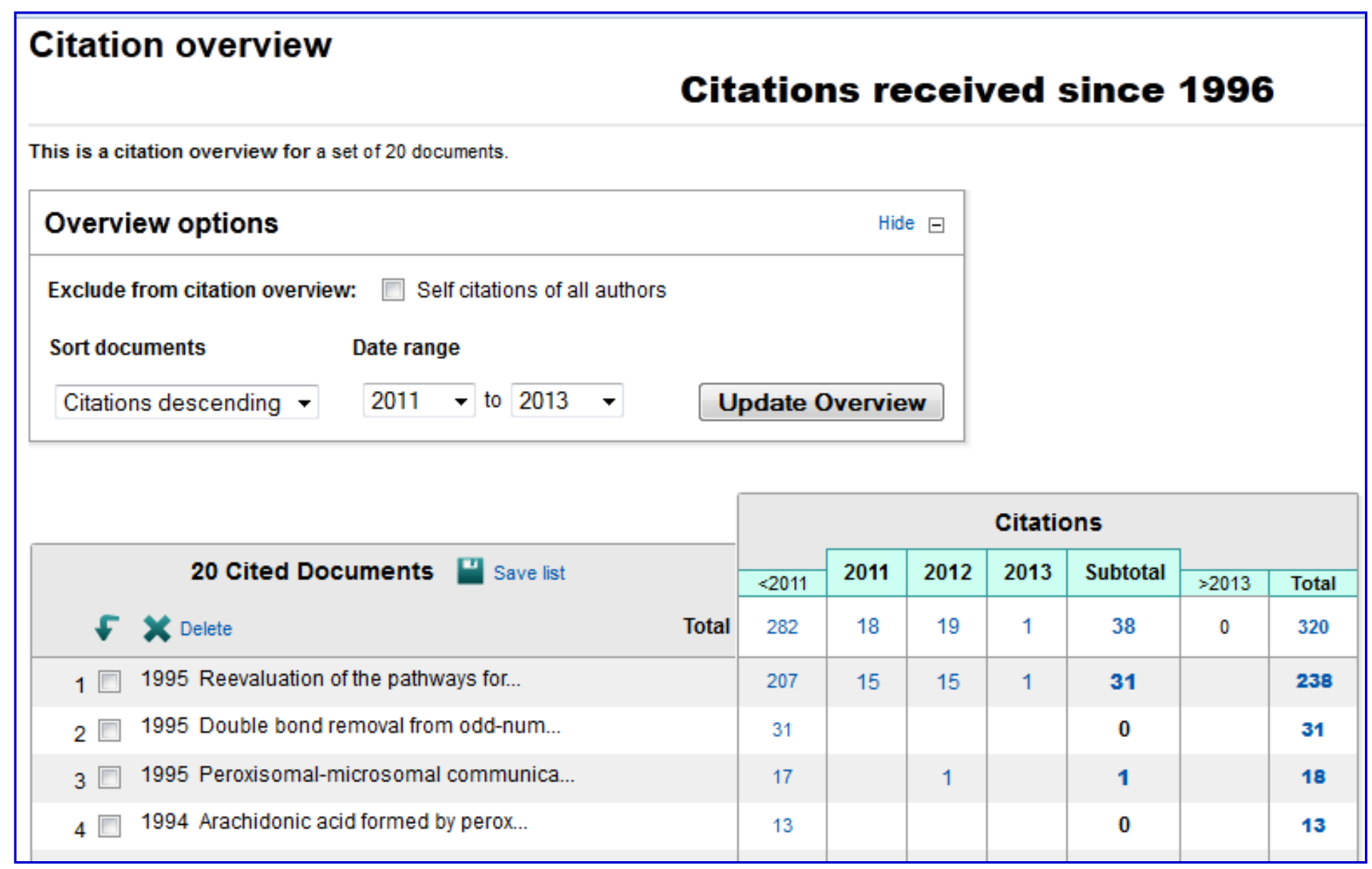




\section{Scopus Tools \& Features}

- Scopus Profiles Feedback Wizard \& ORCID

- Citation Tracker in Scopus

- Author Evaluator Tool 


\section{Select author name to open Author Profile}

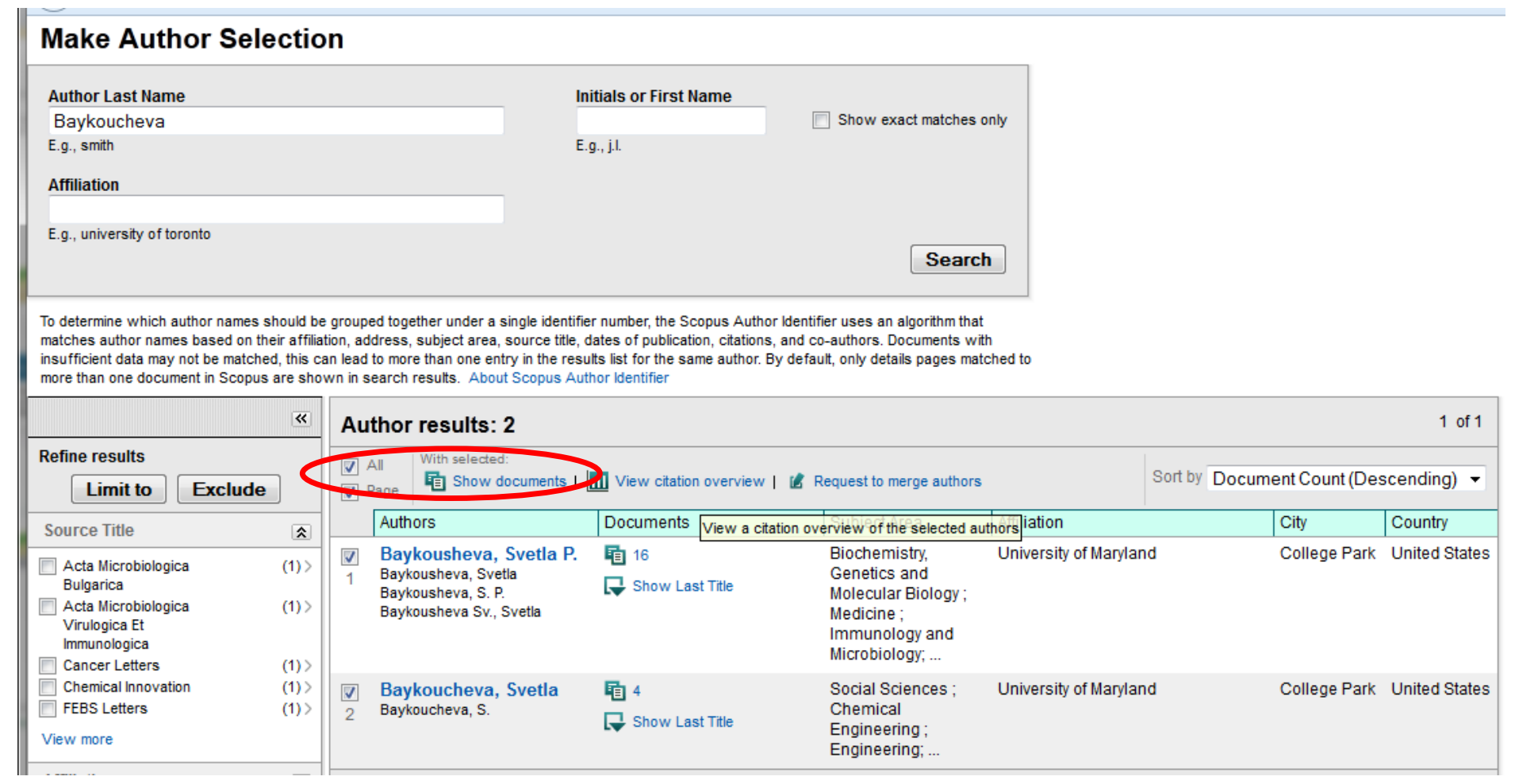




\section{Choose "find potential author matches" to group both profiles}

\section{in real time}

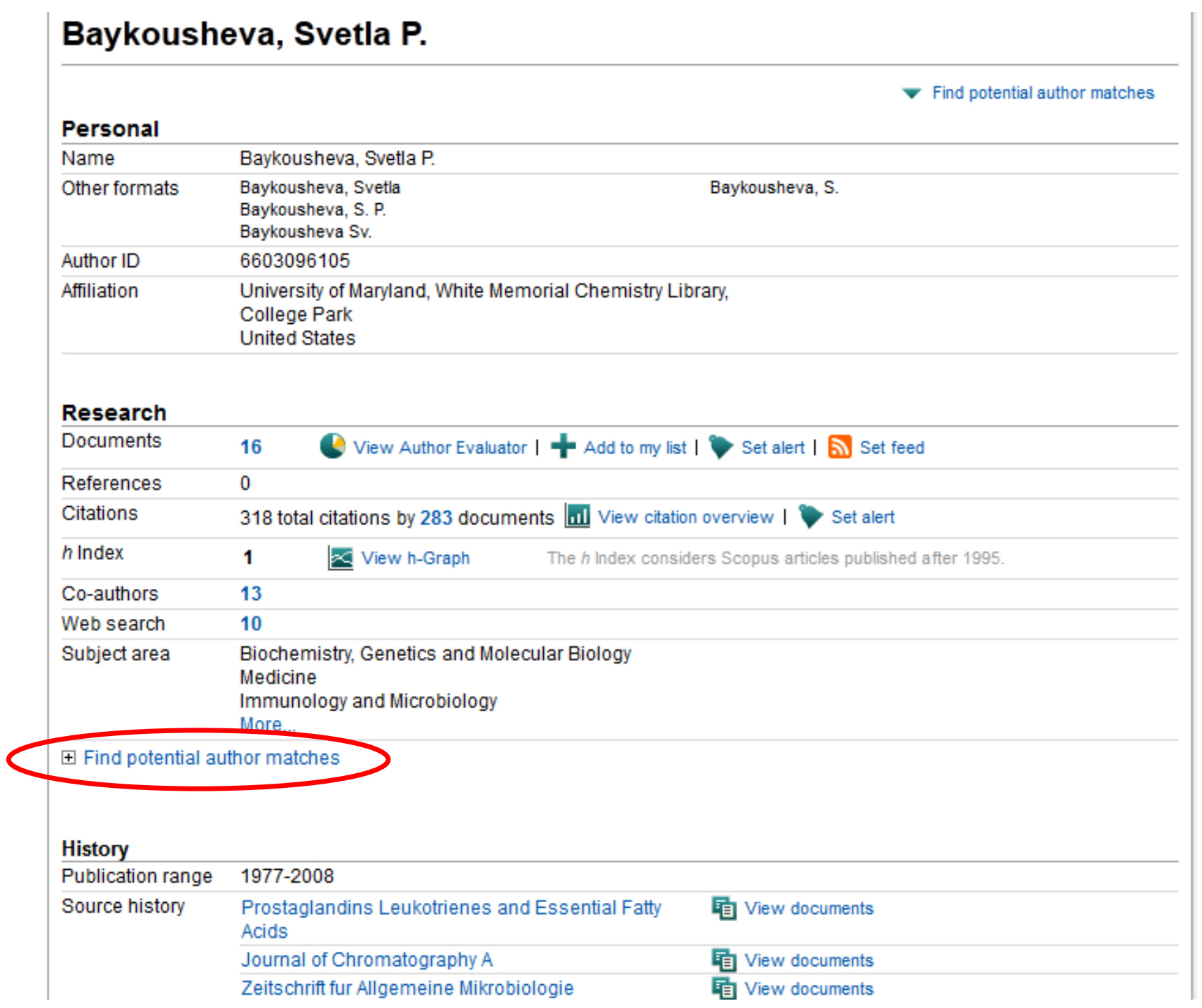




\section{Author Profile recalculates author stats based on grouped profiles}

\begin{tabular}{|c|c|}
\hline \multicolumn{2}{|c|}{ Baykousheva, Svetla P. } \\
\hline & $\nabla$ Find potential author matches \\
\hline \multicolumn{2}{|l|}{ Personal } \\
\hline Name & Baykousheva, Svetla P. \\
\hline Other formats & $\begin{array}{l}\text { Baykousheva, Svetla } \\
\text { Baykousheva, S. P. } \\
\text { Baykousheva Sv. }\end{array}$ \\
\hline Author ID & 6603096105 \\
\hline Affiliation & $\begin{array}{l}\text { University of Maryland, White Memorial Chemistry Library, } \\
\text { College Park } \\
\text { United States }\end{array}$ \\
\hline Research & Baykousheva, Svetla P. \\
\hline Documents & $\begin{array}{l}16 \text { View Author Evaluator } \\
+ \text { Add to my list I }>\text { Set alert }\end{array}$ \\
\hline References & 60 \\
\hline Citations & $\begin{array}{l}318 \text { total citations by } 283 \text { documents } \\
\text { Wl View citation overview I }>\text { Set alert }\end{array}$ \\
\hline$h$ Index & $1 \quad$ View h-Graph \\
\hline & The $h$ Index considers Scopus articles published after 1995 . \\
\hline Co-authors & 13 \\
\hline Web search & 10 \\
\hline Subject area & $\begin{array}{l}\text { Biochemistry, Genetics and Molecular Biology } \\
\text { Medicine } \\
\text { Immunology and Microbiology } \\
\text { More... }\end{array}$ \\
\hline Grouped authors & $\begin{array}{l}\text { You have grouped } 1 \text { potential author matches with Baykousheva, Svetla P. } \\
\text { To store this group in Settings, click Save group. }\end{array}$ \\
\hline
\end{tabular}




\section{Altmetrics}

\section{www.altmetrics.org}

"...the creation and study of new metrics based on the Social Web for analyzing and informing scholarship" Takes into account a new environment:

- Sharing of "raw science" like datasets, code, and experimental designs

- Semantic publishing or "nanopublication," where the citeable unit is an argument or passage rather than entire article.

- Widespread self-publishing via blogging, microblogging, and comments or annotations on existing work. 


\section{Google Scholar Metrics}

- Uses the Google's PageRank algorithm

- Uses the h-index to calculate the impact of journals

- One of the main advantages of Google Scholar is that it is more comprehensive in its scope than Thomson Reuters' Web of Science

- The h-index was created to evaluate individual scholar's impact; not reliable for journals 